\title{
Supportive Care of Patients on Mechanical Ventilation
}

\author{
Martin Urner MD, Bruno L Ferreyro MD, Ghislaine Douflé MD, and Sangeeta Mehta MD
}

\author{
Introduction \\ Sedation and Pain Management \\ Agitation and Delirium \\ Sleep in the ICU \\ The Use of Physical Restraints \\ Early Mobilization \\ Family Engagement \\ Conclusions and Future Challenges
}

\begin{abstract}
The paradigm of supportive care of patients who are critically ill has changed significantly over the past 20 years. Patients on mechanical ventilation are no longer heavily sedated; the goal is a comfortable patient who can interact with health-care professionals and with their family members. Systematic, regular assessment of the patient for pain, anxiety, and sleep deprivation allows early recognition of these distressing symptoms. Appropriate treatment of patients' symptoms should be based on a multimodal pharmacologic and non-pharmacologic approach. Early mobilization and avoidance of physical restraint are additional patient-centered goals. The presence of family members during daily rounds and at the bedside can reduce the distress of the patient and enhance communication with the health-care team. All of these changes have created new challenges and opportunities for the multidisciplinary health-care team. This review aimed to describe the main components of evidence-based supportive care of patients on mechanical ventilation, beyond the specific settings of the ventilator. Key words: intensive care unit; critical illness; sedation; pain; analgesia; delirium; agitation; caregivers; family members; early mobilization. [Respir Care 2018;63(12):1567-1574. () 2018 Daedalus Enterprises]
\end{abstract}

\section{Introduction}

Mechanical ventilation is a life-saving intervention that has evolved and been refined since the second half of the 20th century. Classically, patients on mechanical

Drs Urner, Ferreyro, Douflé, and Mehta are affiliated with the Interdepartmental Division of Critical Care Medicine, University of Toronto, Toronto, Ontario, Canada. Drs Urner and Ferreyro are affiliated with the Institute for Health Policy, Management, and Evaluation, University of Toronto, Toronto, Ontario, Canada. Dr Douflé is affiliated with the Department of Anesthesia, University of Toronto, Toronto, Ontario, Canada. Dr Mehta is affiliated with the Department of Medicine, Sinai Health System and University of Toronto, Toronto, Ontario, Canada.

Drs Urner and Ferreyro contributed equally to this work.

The authors have disclosed no conflicts of interest. ventilation were routinely exposed to deep sedation and even paralysis, with little mobilization. ${ }^{1,2}$ As a consequence of research over the past 2 decades that focused on supportive care, there has been a shift in the paradigm of the management of sedation, mobilization, and family engagement in the ICU. ${ }^{2}$ This review aimed to describe the main components of evidence-based sup-

\footnotetext{
Dr Mehta presented a version of this paper as the 44th Donald F Egan Scientific Memorial Lecture at the 63rd AARC Congress, held October 4-7, 2017, in Indianapolis, Indiana.

Correspondence: Sangeeta Mehta MD, Sinai Health System, 600 University Ave, Suite 18-216, Toronto, ON, Canada M5G 1X5. E-mail: geeta.mehta@utoronto.ca.
}

DOI: $10.4187 /$ respcare.06651 


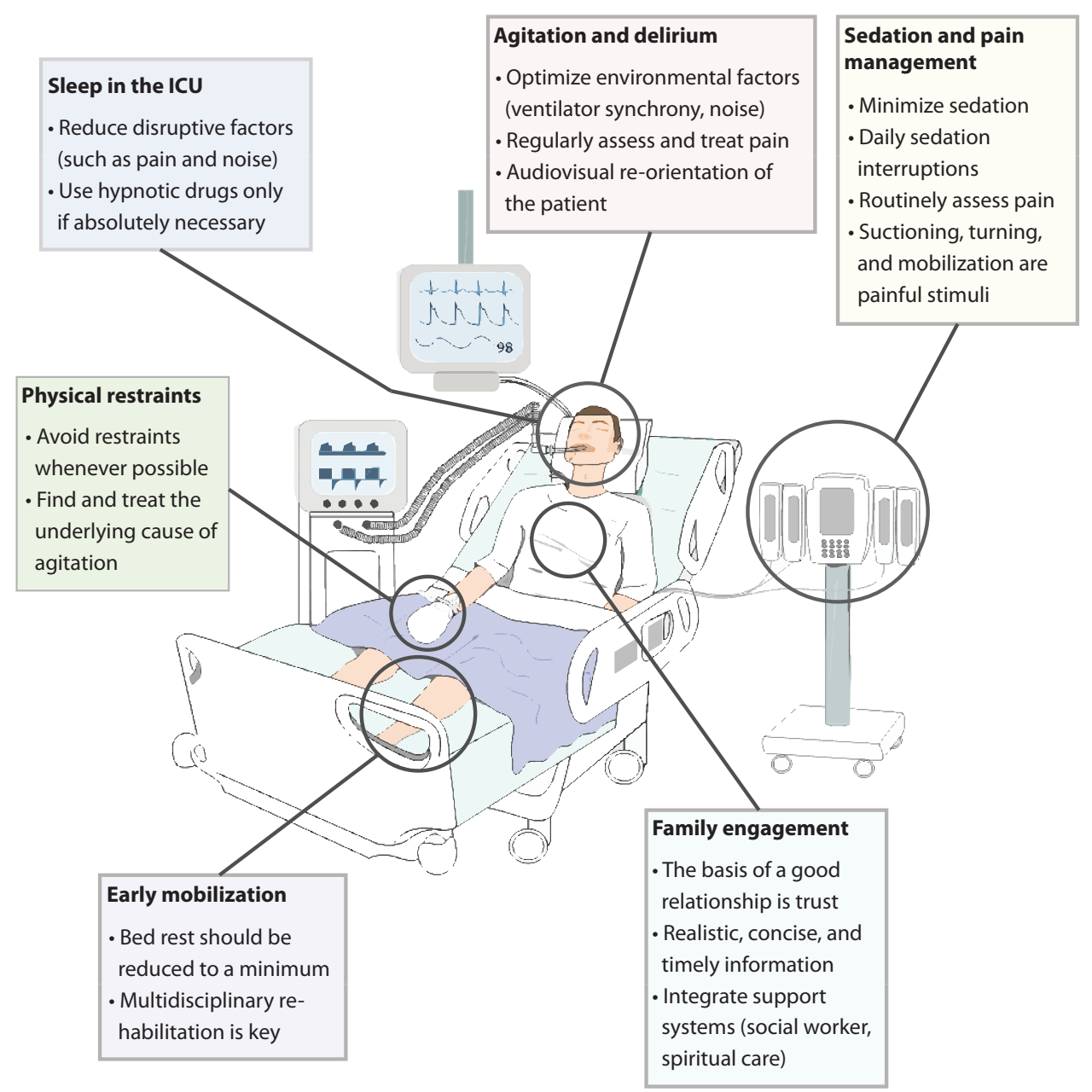

Fig. 1. The main components of evidence-based supportive care of patients on mechanical ventilation.

portive care of patients on mechanical ventilation, beyond the specific settings of the ventilator. For didactic purposes, the text was divided into different sections and addressed each of these components (Fig. 1). However, there is a significant natural overlap between all these management strategies.

\section{Sedation and Pain Management}

Patients who are critically ill and require mechanical ventilation often experience a combination of pain, restlessness, anxiety, and delirium, which is promoted and influenced by a complex interplay of physiologic, pathological, and external factors. ${ }^{3}$ Traditionally, patients in the ICU who undergo mechanical ventilation were heavily sedated and frequently received muscle paralysis. ${ }^{1}$ Sedation management of patients who are critically ill, however, has experienced a dramatic shift during the past 15 years. ${ }^{4}$ There is growing evidence that indicates that prolonged and deep sedation is associated with poor out- comes; ${ }^{3-5}$ whereas minimization of sedation is associated with reduced duration of mechanical ventilation and with shorter ICU and hospital length of stays. ${ }^{6-9}$ Only a small subset of patients in the ICU require deep sedation, mainly those with severe respiratory failure, shock, or intracranial hypertension, and those who require paralysis (usually for the same aforementioned conditions).

Benzodiazepines, propofol, and dexmedetomidine remain the most frequently used agents for sedation of patients in the ICU. ${ }^{10}$ Benzodiazepines' sedative properties are mediated by the gamma-aminobutyric acid (GABA) receptor; maintenance of sedation with benzodiazepines is generally characterized by good cardiovascular safety, with only mild reduction in arterial blood pressure as a response to altered systemic vascular resistance. ${ }^{11,12}$ Benzodiazepines represent a valid option if prolonged deep sedation is needed. They have particularly favorable effects in case of seizures, acute anxiety, and withdrawal syndromes. However, the long half-life (intermittent bolus dosing is preferred over continuous infusion) and active metabolites, 


\section{Supportive Care of Patients on Mechanical Ventilation}

and a potential association with delirium and longer duration of mechanical ventilation are drawbacks of benzodiazepines; therefore, their use is not recommended as a first-line sedative strategy. ${ }^{4}$

As with benzodiazepines, propofol acts through GABA receptors. Propofol is characterized by a fast onset, undergoes rapid metabolism, and has a short half-life, with no bioaccumulation or prolonged sedative effect. Importantly, propofol does not have an analgesic or amnestic effect. Due to the risk of propofol infusion syndrome, prolonged infusions and dosing of $>80 \mu \mathrm{g} / \mathrm{kg} / \mathrm{min}$ should be avoided. ${ }^{13}$ In contrast to benzodiazepines and propofol, dexmedetomidine is a selective $\alpha_{2}$-receptor agonist that has gained use in recent years. One of the benefits of this agent is that it can induce sedation without significant respiratory depression. ${ }^{3}$ The main adverse effect is bradycardia. The use of dexmedetomidine may be associated with less delirium ${ }^{14}$ and reduced duration of mechanical ventilation, ${ }^{15}$ but strong evidence is still lacking.

Sedation should always be delivered in a patient goaldirected manner by using a validated sedation assessment tool, such as the Richmond Agitation-Sedation Scale or the Riker Sedation-Agitation Scale. ${ }^{11,12,16}$ For most patients who receive mechanical ventilation in the ICU, a reasonable target is a Richmond Agitation-Sedation Scale score of -2 to 0 or a Riker Sedation-Agitation Scale score of 3-4; both targets are representative of a calm, interactive or lightly sedated patient. The use of sedation protocols and a daily wake-up trial have each been associated with reduced duration of mechanical ventilation, and the ICU and hospital lengths of stay.,16-19 This evidence is reflected by a statement in Choosing Wisely Top 5 List in Critical Care Medicine ${ }^{20}$ from multiple critical care societies: "Do not deeply sedate mechanically ventilated patients without a specific indication and without daily attempts to lighten sedation." Independent of the pharmacologic strategy chosen for patients who are receiving invasive mechanical ventilation, it is currently recommended to maintain a light level of sedation that aims for an interactive and calm patient. $2,4,5$

In 2010, Strøm et al, ${ }^{9}$ in a randomized controlled pilot trial, showed that a no-sedation strategy was feasible in the majority of mechanically ventilated subjects and had beneficial effects compared with usual care, including reduced duration of mechanical ventilation and reduced ICU and total hospital length of stays. An important current general principle for patient comfort management is "analgesia first." If a sedative agent is required in addition to analgesia, then the lightest level of sedation should be targeted. Neither lighter sedation, daily wake-up trials, nor no-sedation strategies have been shown to increase the risk of long-term psychological complications in patients on mechanical ventilation. ${ }^{4,5,9,21}$ These insights have led to a change in practice, with patients being awake and able to interact during mechanical ventilation, and have also created new challenges for the multidisciplinary health-care team. Patients on mechanical ventilation frequently experience significant pain and anxiety but may have limited ability to communicate their comfort needs.

Pain is one of the most common unpleasant memories that patients retain from their ICU experience, ${ }^{3,5}$ and the vast majority of patients experience pain during their ICU stay. 3,22 The approach to pain in patients who are critically ill involves 3 different components: prevention, assessment, and treatment. Of these, the identification and objective assessment of pain represent significant challenges for the ICU team. Self-reported pain is considered the reference standard for pain assessment, ${ }^{4}$ but patients on mechanical ventilation often exhibit limitations in expressing their pain. Clinical practice guidelines suggest that pain should be routinely assessed in the ICU, and, if impossible to assess from a patient's self-report, then behavioral pain assessment tools should be incorporated. ${ }^{4}$ Our knowledge about the underlying biologic mechanisms of pain is still limited, and patients in the ICU often experience a combination of different types of specific pain components. ${ }^{23}$

In mechanically ventilated patients, it is particularly difficult to assess if the type of pain is acute or chronic and whether a nociceptive or neuropathic component is predominant. Ultimately, pain management of patients in the ICU should always comprise a multimodal approach that involves pharmacologic and nonpharmacologic interventions. Painful stimuli in patients on mechanical ventilation include suctioning, turning, mobilization, catheter insertion, and wound care. ${ }^{22}$ Pain due to these stimuli should be anticipated and prevented with pharmacologic analgesia. In patients who are critically ill, opioids are the most common pharmacologic agents for pain and are first-line agents for non-neuropathic pain; generally intermittent rather than continuous dosing is preferred. ${ }^{4}$ Non-opioid analgesics, such as acetaminophen and nonsteroidal anti-inflammatory drugs, can be used as opioidsparing agents. ${ }^{4}$ Non-pharmacologic interventions include relaxation techniques and music therapy, and there is evidence that indicates an opioid-sparing effect. ${ }^{22}$

\section{Agitation and Delirium}

Delirium is defined as an acute disturbance in attention and awareness, with additional disturbances in cognition, not explained by a preexisting neurocognitive disorder or caused by another medical condition. ${ }^{24,25}$ In patients who are critically ill, the term delirium has been used ambiguously to describe different neurological states, such as encephalopathy and acute brain failure. ${ }^{3}$ Delirium is associated with increased mortality and with long-term sequelae, for example, post-ICU cognitive impairment. ${ }^{26,27}$ 


\section{Supportive Care of Patients on Mechanical Ventilation}

Identification of delirium is crucial to identify reversible precipitants and to implement environmental measures. Nevertheless, delirium is often not diagnosed in patients on mechanical ventilation. ${ }^{3,28}$ Currently, the two most commonly used validated tools for the assessment of delirium in the ICU are the Confusion Assessment Method for the ICU $^{29}$ and the Intensive Care Delirium Screening Checklist. ${ }^{30}$ They both have shown similar sensitivity for detection of delirium compared with Diagnostic and Statistical Manual of Mental Disorders criteria, ${ }^{31}$ although the Confusion Assessment Method for the ICU ${ }^{29}$ has higher specificity. ${ }^{3}$ Delirium cannot be attributed to a single precipitating factor but is likely always of multifactorial etiology. Important precipitating factors for delirium include acute illness, exposure to medications, withdrawal syndromes, and environmental factors (sleep deprivation, noise from monitors). In particular, some studies indicate that continuous infusions of benzodiazepines, opioids, and corticosteroids have been associated with the development of delirium in subjects on mechanical ventilation. ${ }^{4,25}$

The treatment of the underlying critical illness that necessitated ICU admission is crucial for delirium resolution. Patient-ventilator asynchrony should be avoided during mechanical ventilation, pain management optimized, and early mobilization attempted to minimize environmental factors that trigger delirium. ${ }^{31}$ Simple non-pharmacologic interventions that may be helpful include frequently reorientating the patient; maintaining a normal day-night routine; and ensuring that the patient has his or her hearing aids, eyeglasses, and dentures. A single randomized controlled trial showed faster delirium resolution, less agitation, and a greater rate of transfer home or to rehabilitation when the subjects were treated with quetiapine, in addition to as-needed haloperidol. ${ }^{33}$ However, there is no definitive evidence that specific pharmacologic interventions, such as the administration of haloperidol or atypical antipsychotics, prevent or reduce the duration of delirium in patients on mechanical ventilation. ${ }^{26,34,35}$

\section{Sleep in the ICU}

Patients who require mechanical ventilation experience sleep deprivation, which is explained by a combination of multiple factors that can be classified broadly as environmental and non-environmental. ${ }^{36-38}$ Environmental factors may include noise disruption, patient-care monitoring (blood pressure, blood sampling, diagnostic testing), and 24-h light exposure. Non-environmental factors include acute illness, pain, medical equipment (eg, endotracheal tube, nasogastric tubes, urinary catheters), and medications, particularly psychotropics. ${ }^{37,38}$

The typical sleep architecture involves a period of rapid eye movement and a period of non-rapid eye movement, which is subdivided into 3 phases: N1, N2, and N3. The rapid eye movement stage usually accounts for 15 to $20 \%$ of sleep time and is associated with active dreaming. ${ }^{39}$ This physiological sleep architecture is severely altered in mechanically ventilated patients. ${ }^{37,40}$ In this setting, sleep is usually fragmented with frequent arousals, decreased rapid eye movement and N3 sleep, and an increase in the N1 stage. ${ }^{36}$ There is evidence that patients in the ICU who experience poor sleep quality have an increased risk of poor outcomes, possibly related to the association of sleep deprivation, with decreased ability to resist infections, reduced pain tolerance, short-term memory loss, and cognitive impairment. ${ }^{40}$ It has also been shown that sleep deprivation in the ICU setting is an independent risk factor for delirium. ${ }^{41}$

There is a paucity of data on successful interventions to improve sleep duration and quality in patients on mechanical ventilation, which is likely due to the challenges of measuring sleep in patients who are critically ill. Although, with the lack of strong evidence from randomized controlled trials, there are specific interventions that will logically improve the patient's experience in the ICU. ${ }^{39}$ The adequate treatment of acute illness, review of concomitant medications and prescription regimen for polypharmacy, and reduction of nighttime interruptions are some examples. ${ }^{4}$ With regard to pharmacologic interventions, although these are widely used in the ICU setting, there is no evidence of any beneficial drug to improve sleep in this setting. ${ }^{4}$ Hypnotic drugs, when absolutely necessary, should be individualized and selected based on the patient's condition, age, comorbidities, potential interactions, and preICU use of sleep aids. In our ICU, melatonin is often the first-line agent because it is well tolerated and associated with minimal adverse effects. However, 2 recent systematic reviews found insufficient evidence for the use of melatonin and propofol, to promote sleep in the ICU. ${ }^{42,43}$

\section{The Use of Physical Restraints}

Restraints are defined as any method, physical or mechanical device, material, or equipment that immobilizes or reduces the ability of a patient to move his or her arms, legs, body, or head freely. ${ }^{44}$ Despite the existence of guidelines that recommend physical restraint minimization, restraining patients is still a common practice in many ICUs around the world, with vast regional and between-hospital differences in the prevalence of physical restraints..$^{45,46}$ The restraint of a person-and patients who are critically ill are among the most vulnerable persons-represents a very aggressive measure and should be the very last (and temporary) option for the prevention of self-harm or harm to others. ${ }^{47}$ Clinicians often justify the use of restraints for prevention of patient-initiated device removal, unplanned extubation, or disruption of life-sustaining therapies. ${ }^{46,47}$ However, results of some studies indicate that restraints do 


\section{Supportive Care of Patients on Mechanical Ventilation}

not prevent accidental device removal. ${ }^{48,49}$ Mechanical ventilation, sedation (especially benzodiazepine use), delirium, and large ICUs with a lower nurse-to-patient ratio are common factors associated with the use of restraints. ${ }^{50,51}$ Interestingly, no patient-specific characteristics were found to be related to the use of restraints, which indicates that their use seems to be mainly associated with treatment characteristics and modalities. ${ }^{30}$

The use of restraints in the ICU not only causes patient stress, anxiety, increased oxygen consumption, elevated heart rate, and hypertension ${ }^{52}$ but may also have detrimental long-term consequences, as illustrated by Jones et al ${ }^{53}$ in a multi-center follow-up study of subjects after ICU discharge. Physical restraints and prolonged sedation were associated with the development of posttraumatic stress disorder independent of case mix and illness severity. Therefore, the goal must be to avoid or reduce the use of restraints whenever possible. To achieve this goal, a multimodal non-pharmacologic and pharmacologic approach should be used for patients who are agitated, with sedative infusions in the short term and on a longer term with the treatment of the underlying condition that causes agitation. Pain is the most frequent cause of agitation and, consequently, should be assessed and treated. ${ }^{54}$ Anxiety should be addressed with non-pharmacologic approaches and, if necessary, in the acute setting, with intermittent administration of low doses of benzodiazepines. Furthermore, iatrogenic and non-iatrogenic substance withdrawal should always be considered as a potential precipitant for agitation and delirium, and should be assessed and treated. ${ }^{53}$

\section{Early Mobilization}

When patients who are critically ill are admitted to the ICU, clinicians primarily focus on hemodynamic stabilization and recovery from acute organ failure. ${ }^{18}$ Patients often require mechanical ventilation and receive sedatives to minimize distress and oxygen consumption. Furthermore, given the invasive life-support systems connected to the patients, sedation is reduced only hesitantly due to concern for accidental self-extubation or unplanned disconnection from life-support systems. ${ }^{56}$ Also, bed rest was traditionally espoused as a treatment that supports the patient toward recovery from critical illness.

However, there is little evidence for bed rest as a form of treatment to recover from critical illness. In fact, complete bed rest is a highly non-physiological and harmful form of therapy, and patients should be mobilized as early as possible. ${ }^{57} \mathrm{~A}$ variety of detrimental effects have been observed after prolonged periods of bed rest, such as muscular atrophy and remodeling (which includes changes in myosin fibers) as well as various alterations in energy metabolism. ${ }^{58}$ Regardless of nutritional support, patients who are critically ill experience a dramatic loss of skeletal muscle mass, especially in the first weeks of immobilization. ${ }^{59}$ Bed rest for as little as $7 \mathrm{~d}$ is associated with substantial resistance to effects of insulin on glucose metabolism. ${ }^{58}$ Immobilization has also been shown to induce orthostatic intolerance, which might be related to an attenuation of the vestibulosympathetic reflex observed after prolonged bed rest. ${ }^{61}$

Observational studies in subjects who survived ICU stay reveal that long-term sequelae of immobilization included persistent physical impairments and incomplete recovery of neuromuscular function. ${ }^{18,62}$ In a cohort of subjects with ARDS who survived ICU stay, Herridge et al ${ }^{63}$ observed that lung function returned to levels comparable with the healthy population, but physical limitations and varying degrees of exercise weakness were among the most-significant long-term burdens. Mobilization and physical activity may have a beneficial influence in states of severe systemic inflammation by protecting muscles and may ultimately result in improved functional outcome after critical illness. ${ }^{64}$ Therefore, the prevention of neuromuscular dysfunction by reducing bed rest and implementing early mobilization is of crucial importance for patients who are critically ill.

Safety concerns are often cited to justify the decision not to mobilize patients who are critically ill and on mechanical ventilation. However, Bailey et al ${ }^{65}$ demonstrated, in cohort of subjects with respiratory failure, that early activity was feasible and safe. Of those subjects who survived ICU admission, the majority (69\%) were able to ambulate $>100$ feet at the time of ICU discharge. Thomsen et $\mathrm{al}^{66}$ showed that unnecessary immobilization throughout the course of acute respiratory failure could be avoided by using an early activity protocol and by minimizing administration of sedatives. Burtin et al ${ }^{67}$ implemented daily exercise sessions for subjects who were critically ill by using a bedside cycle ergometer and observed beneficial effects on functional exercise capacity and recovery of muscle force at hospital discharge. Schweickert et $\mathrm{al}^{68}$ demonstrated that mobilization in the earliest days of critical illness was safe and well tolerated, and, most importantly, reduced the incidence of delirium and duration of mechanical ventilation, and led to a better functional outcome at hospital discharge.

Altogether, there is moderate evidence that early mobilization is safe, may improve functional outcomes, and may reduce the occurrence of delirium in patients with critical illness. There is certainly a need for more research in this area, given the mixed results from published trials, likely related to heterogeneous patient populations and differences in intensity and timing of the start of mobilization. Bed rest should be reduced to a minimum and early involvement of a multidisciplinary rehabilitation team during the ICU stay might be one of 


\section{Supportive Care of Patients on Mechanical Ventilation}

the multiple strategies to reduce the long-term sequelae of critical illness.

\section{Family Engagement}

Family engagement has been defined as an active partnership between caregivers and relatives. ${ }^{69}$ In the critical care setting and, especially during the early phases of critical illness, patients are often unable to express themselves; hence, patient-centered care is inseparably tied to the concept of family-centered care. When the severity of illness or delirium prevents the patient from verbalizing his or her wishes, the ICU team turns to family members to speak on behalf of the patient. A broad spectrum exists regarding the degree of family involvement in the care of their relatives, which mainly reflects different types of relationships among the patients, families, and ICU team. ${ }^{70,71}$ The current standard of care is an approach that emphasizes interactivity and empowerment of the patient and family members.

A family engagement concept in the critical care setting consists of a multidisciplinary framework, which involves physicians, nurses, social workers, and spiritual care. Multiple opportunities are available at different levels to support families during the patient's critical illness and admission to ICU. These include providing realistic, consistent, and timely information about diagnosis, treatment, and prognosis; encouraging the presence of the family during nursing and medical rounds; enabling family members to assist with direct patient care; providing a variety of resources and support systems (eg, social services, spiritual care); and being sensitive to family members' personal comfort needs (eg, waiting-room environment). ${ }^{72}$

There is little evidence that directly links family engagement to improved patient outcomes. ${ }^{73}$ However, critical illness may lead to significant anxiety and depression among family members, inherent to the severity of patients' condition and the likelihood of unfavorable outcomes. ${ }^{74}$ Therefore, there are potential important benefits to both patient and family members of increased family engagement in the ICU. ${ }^{75-79}$ Better engagement and involvement of the families of patients who are critically ill is associated with higher levels of family satisfaction. ${ }^{71}$ Furthermore, establishing a trusting partnership between families and the treatment team ultimately serves a common goal, which is the patient's recovery from critical illness. A trusting partnership is also of utmost importance to approach sensitive topics for patients and their families, such as participation in research studies and goals of care discussions.

\section{Conclusions and Future Challenges}

During the past 20 years, there has been a significant change in the paradigm of supportive care of patients who are critically ill, with improvements in the assessment, prevention, and treatment of pain, agitation, and delirium. This was facilitated by a global increased interest in patient and family centered care, which led to landmark clinical trials and clinical practice guidelines. ${ }^{6-8}$ Incorporating evidence-based strategies in daily practice remains challenging for ICU teams. Local understanding of the best effective interventions for culture change and knowledge translation, and interprofessional collaboration are crucial for the implementation of evidence-based medicine. Overall, patients who are critically ill are best treated with minimum to no sedation and should receive multimodal pain therapy, while considering potential painful stimuli, such as suctioning or early mobilization. Targeted pain management and the optimization of environmental factors have a positive effect on sleep and the development of ICU delirium. Family members play a key role in the recovery process and should be actively involved in patient care. A good relationship with the family should be sought and is based on mutual trust because the treatment team as well as the family share a common goal, which is in providing the best support for the patient who is critically ill.

\section{REFERENCES}

1. Hansen-Flaschen JH, Brazinsky S, Basile C, Lankin PN. Use of sedating drugs and neuromuscular blocking agents in patients requiring mechanical ventilation for respiratory failure. A national survey. Survey of Anesthesiology 1992;36(4):246-2875.

2. Shehabi Y, Bellomo R, Mehta S, Riker R, Takala J. Intensive care sedation: the past, present and the future. Crit Care 2013;17(3):322.

3. Reade MC, Finfer S. Sedation and delirium in the intensive care unit. N Engl J Med 2014;370(5):444-454.

4. Barr J, Fraser GL, Puntillo K, Ely EW, Gélinas C, Dasta JF, et al.; American College of Critical Care Medicine. Clinical practice guidelines for the management of pain, agitation, and delirium in adult patients in the intensive care unit. Crit Care Med 2013;41(1):263306.

5. Moreira FT, Serpa Neto A. Sedation in mechanically ventilated patients-time to stay awake? Ann Transl Med 2016;4(19):382.

6. Girard TD, Kress JP, Fuchs BD, Thomason JW, Schweickert WD, Pun BT, et al. Efficacy and safety of a paired sedation and ventilator weaning protocol for mechanically ventilated patients in intensive care (Awakening and Breathing Controlled trial): a randomised controlled trial. Lancet 2008;371(9607):126-134.

7. Kress JP, Pohlman AS, O'Connor MF, Hall JB. Daily interruption of sedative infusions in critically ill patients undergoing mechanical ventilation. N Engl J Med 2000;342(20):1471-1477.

8. Mehta S, Burry L, Cook D, Fergusson D, Steinberg M, Granton J, et al.; SLEAP Investigators, Canadian Critical Care Trials Group. Daily sedation interruption in mechanically ventilated critically ill patients cared for with a sedation protocol: a randomized controlled trial. JAMA 2012;308(19):1985-1992. 


\section{Supportive Care of Patients on Mechanical Ventilation}

9. Strøm T, Martinussen T, Toft P. A protocol of no sedation for critically ill patients receiving mechanical ventilation: a randomised trial. Lancet 2010;375(9713):475-480.

10. Payen JF, Chanques G, Mantz J, Hercule C, Auriant I, Leguillou JL, et al. Current practices in sedation and analgesia for mechanically ventilated critically ill patients: a prospective multicenter patientbased study. Anesthesiology 2007;106(4):687-695; quiz 891-982.

11. Schulte-Sasse U, Hess W, Tarnow J. Haemodynamic responses to induction of anaesthesia using midazolam in cardiac surgical patients. Br J Anaesth 1982;54(10):1053-1058.

12. Olkkola KT, Ahonen J. Midazolam and other benzodiazepines. Handb Exp Pharmacol 2008;(182):335-360.

13. Fodale V, La Monaca E. Propofol infusion syndrome: an overview of a perplexing disease. Drug Saf 2008;31(4):293-303.

14. Riker RR, Shehabi Y, Bokesch PM, Ceraso D, Wisemandle W, Koura F, et al.; SEDCOM (Safety and Efficacy of Dexmedetomidine Compared With Midazolam) Study Group. Dexmedetomidine vs midazolam for sedation of critically ill patients: a randomized trial. JAMA 2009;301(5):489-499.

15. Jakob SM, Ruokonen E, Grounds RM, Sarapohja T, Garratt C, Pocock SJ, et al.; Dexmedetomidine for Long-Term Sedation Investigators. Dexmedetomidine vs midazolam or propofol for sedation during prolonged mechanical ventilation: two randomized controlled trials. JAMA 2012;307(11):1151-1160.

16. Riker RR, Picard JT, Fraser GL. Prospective evaluation of the Sedation-Agitation Scale for adult critically ill patients. Crit Care Med 1999;27(7):1325-1329.

17. Brook AD, Ahrens TS, Schaiff R, Prentice D, Sherman G, Shannon W, Kollef MH. Effect of a nursing-implemented sedation protocol on the duration of mechanical ventilation. Crit Care Med 1999; 27(12):2609-2615.

18. Kress JP. Clinical trials of early mobilization of critically ill patients. Crit Care Med 2009;37(10 Suppl):S442-S447.

19. Treggiari MM, Romand JA, Yanez ND, Deem SA, Goldberg J, Hudson L, et al. Randomized trial of light versus deep sedation on mental health after critical illness. Crit Care Med 2009;37(9):25272534.

20. Halpern SD, Becker D, Curtis JR, Fowler R, Hyzy R, Kaplan LJ, et al.; Choosing Wisely Taskforce, American Thoracic Society, American Association of Critical-Care Nurses, Society of Critical Care Medicine. An official American Thoracic Society/American Association of Critical-Care Nurses/American College of Chest Physicians/Society of Crit Care Med policy statement: the Choosing Wisely ${ }^{\circledR}$ top 5 list in critical care medicine. Am J Respir Crit Care Med 2014;190(7):818-826.

21. Jackson JC, Girard TD, Gordon SM, Thompson JL, Shintani AK, Thomason JW, et al. Long-term cognitive and psychological outcomes in the awakening and breathing controlled trial. Am J Respir Crit Care Med 2010;182(2):183-191.

22. Erstad BL, Puntillo K, Gilbert HC, Grap MJ, Li D, Medina J, et al. Pain management principles in the critically ill. Chest 2009;135(4): 1075-1086.

23. Kent ML, Tighe PJ, Belfer I, Brennan TJ, Bruehl S, Brummett CM, et al. The ACTTION-APS-AAPM Pain Taxonomy (AAAPT) Multidimensional Approach to Classifying Acute Pain Conditions. J Pain 2017;18(5):479-489.

24. Oldham MA, Flanagan NM, Khan A, Boukrina O, Marcantonio ER. Responding to ten common delirium misconceptions with best evidence: an educational review for clinicians. J Neuropsychiatry Clin Neurosci 2018;30(1):51-57.

25. Slooter AJ, Van De Leur RR, Zaal IJ. Delirium in critically ill patients. Handb Clin Neurol 2017;141:449-466.

26. van den Boogaard M, Schoonhoven L, Evers AW, van der Hoeven JG, van Achterberg T, Pickkers P. Delirium in critically ill patients: impact on long-term health-related quality of life and cognitive functioning. Crit Care Med 2012;40(1):112-118.

27. Faria Rda S, Moreno RP. Delirium in intensive care: an underdiagnosed reality. Rev Bras Ter Intensiva 2013;25(2):137-147.

28. Arumugam S, El-Menyar A, Al-Hassani A, Strandvik G, Asim M, Mekkodithal A, et al. Delirium in the intensive care unit. J Emerg Trauma Shock 2017;10(1):37-46.

29. Ely EW, Margolin R, Francis J, May L, Truman B, Dittus R, et al. Evaluation of delirium in critically ill patients: validation of the Confusion Assessment Method for the Intensive Care Unit (CAMICU). Crit Care Med 2001;29(7):1370-1379.

30. Andrews L, Silva SG, Kaplan S, Zimbro K. Delirium monitoring and patient outcomes in a general intensive care unit. Am J Crit Care 2015;24(1):48-56.

31. American Psychiatric Association. Diagnostic and statistical manual of mental disorders (5th ed.). Arlington, VA: American Psychiatric Publishing;2013.

32. Strøm T, Toft P. Sedation and analgesia in mechanical ventilation. Semin Respir Crit Care Med 2014;35(4):441-450.

33. Devlin JW, Roberts RJ, Fong JJ, Skrobik Y, Riker RR, Hill NS, et al. Efficacy and safety of quetiapine in critically ill patients with delirium: a prospective, multicenter, randomized, double-blind, placebo-controlled pilot study. Crit Care Med 2010;38(2):419-427.

34. Girard TD, Pandharipande PP, Carson SS, Schmidt GA, Wright PE, Canonico AE, et al.; MIND Trial Investigators. Feasibility, efficacy, and safety of antipsychotics for intensive care unit delirium: the MIND randomized, placebo-controlled trial. Crit Care Med 2010; 38(2):428-437.

35. Neufeld KJ, Yue J, Robinson TN, Inouye SK, Needham DM. Antipsychotic medication for prevention and treatment of delirium in hospitalized adults: a systematic review and meta-analysis. J Am Geriatr Soc 2016;64(4):705-714

36. Cooper AB, Thornley KS, Young GB, Slutsky AS, Stewart TE, Hanly PJ. Sleep in critically ill patients requiring mechanical ventilation. Chest 2000;117(3):809-818.

37. Figueroa-Ramos MI, Arroyo-Novoa CM, Lee KA, Padilla G, Puntillo KA. Sleep and delirium in ICU patients: a review of mechanisms and manifestations. Intensive Care Med 2009;35(5):781-795.

38. Gabor JY, Cooper AB, Crombach SA, Lee B, Kadikar N, Bettger HE, Hanly PJ. Contribution of the intensive care unit environment to sleep disruption in mechanically ventilated patients and healthy subjects. Am J Respir Crit Care Med 2003;167(5):708-715.

39. Carley DW, Farabi SS. Physiology of sleep. Diabetes Spectr 2016; 29(1):5-9.

40. Pisani MA, Friese RS, Gehlbach BK, Schwab RJ, Weinhouse GL, Jones SF. Sleep in the intensive care unit. Am J Respir Crit Care Med 2015;191(7):731-738.

41. Helton MC, Gordon SH, Nunnery SL. The correlation between sleep deprivation and the intensive care unit syndrome. Heart Lung 1980; 9(3):464-468.

42. Lewis SR, Schofield-Robinson OJ, Alderson P, Smith AF. Propofol for the promotion of sleep in adults in the intensive care unit. Cochrane Database Syst Rev 2018;1:CD012454.

43. Lewis SR, Pritchard MW, Schofield-Robinson OJ, Alderson P, Smith AF. Melatonin for the promotion of sleep in adults in the intensive care unit. 2018;5:CD012455.

44. Centers for Medicare \& Medicaid Services (CMS), DHHS. Medicare and Medicaid programs; hospital conditions of participation: patients' rights. Final rule. Fed Regist 2006;71(236):71377-71428.

45. Martin B, Mathisen L. Use of physical restraints in adult critical care: a bicultural study. Am J Respir Crit Care 2005;14(2):133-142.

46. Benbenbishty J, Adam S, Endacott R. Physical restraint use in intensive care units across Europe: the PRICE study. Intensive Crit Care Nurs 2010;26(5):241-245. 


\section{Supportive Care of Patients on Mechanical Ventilation}

47. Hine K. The use of physical restraint in critical care. Nurs Crit Care 2007;12(1):6-11.

48. Chevron V, Ménard JF, Richard JC, Girault C, Leroy J, Bonmarchand G. Unplanned extubation: risk factors of development and predictive criteria for reintubation. Crit Care Med 1998;26(6):10491053.

49. Mion LC, Minnick AF, Leipzig R, Catrambone CD, Johnson ME. Patient-initiated device removal in intensive care units: a national prevalence study. Crit Care Med 2007;35(12):2714-2720; quiz 2725.

50. Luk E, Sneyers B, Rose L, Perreault MM, Williamson DR, Mehta S, et al. Predictors of physical restraint use in Canadian intensive care units. Crit Care 2014;18(2):R46.

51. Micek ST, Anand NJ, Laible BR, Shannon WD, Kollef MH. Delirium as detected by the CAM-ICU predicts restraint use among mechanically ventilated medical patients. Crit Care Med 2005;33(6): 1260-1265.

52. Tate JA, Devito Dabbs A, Hoffman LA, Milbrandt E, Happ MB. Anxiety and agitation in mechanically ventilated patients. Qual Health Res 2012;22(2):157-173.

53. Jones C, Bäckman C, Capuzzo M, Flaatten H, Rylander C, Griffiths RD. Precipitants of post-traumatic stress disorder following intensive care: a hypothesis generating study of diversity in care. Intensive Care Med 2007;33(6):978-985.

54. Chanques G, Jaber S, Barbotte E, Violet S, Sebbane M, Perrigault $\mathrm{PF}$, et al. Impact of systematic evaluation of pain and agitation in an intensive care unit. Crit Care Med 2006;34(6):1691-1699.

55. Lucidarme O, Seguin A, Daubin C, Ramakers M, Terzi N, Beck P, et al. Nicotine withdrawal and agitation in ventilated critically ill patients. Crit Care 2010;14(2):R58.

56. Powers J. A sedation protocol for preventing patient self-extubation. Dimens Crit Care Nurs 1999;18(2):30-34.

57. Dock W. The evil sequelae of complete bed rest. JAMA 1944; 125(16):1083-1085

58. Stein TP, Wade CE. Metabolic consequences of muscle disuse atrophy. J Nutr 2005;135(7):1824S-1828S.

59. Gruther W, Benesch T, Zorn C, Paternostro-Sluga T, Quittan M, Fialka-Moser V, et al. Muscle wasting in intensive care patients: ultrasound observation of the M. quadriceps femoris muscle layer. J Rehabil Med 2008;40(3):185-189.

60. Hill AG, Hill GL. Metabolic response to severe injury. Br J Surg 1998;85(7):884-890.

61. Dyckman DJ, Sauder CL, Ray CA. Effects of short-term and prolonged bed rest on the vestibulosympathetic reflex. Am J Physiol Heart Circ Physiol 2012;302(1):H368-H374.

62. Herridge MS, Chu LM, Matte A, Tomlinson G, Chan L, Thomas C, et al.; RECOVER Program Investigators (Phase 1: towards RECOVER), Canadian Critical Care Trials Group. The RECOVER Program: disability risk groups and 1-year outcome after 7 or more days of mechanical ventilation. Am J Respir Crit Care Med 2016;194(7):831-844.

63. Herridge MS, Tansey CM, Matté A, Tomlinson G, Diaz-Granados N, Cooper A, et al.; Canadian Critical Care Trials Group. Functional disability 5 years after acute respiratory distress syndrome. N Engl J Med 2011;364(14):1293-1304.

64. Winkelman C. Inactivity and inflammation in the critically ill patient. Crit Care Clin 2007;23(1):21-34.
65. Bailey P, Thomsen GE, Spuhler VJ, Blair R, Jewkes J, Bezdjian L, et al. Early activity is feasible and safe in respiratory failure patients. Crit Care Med 2007;35(1):139-145.

66. Thomsen GE, Snow GL, Rodriguez L, Hopkins RO. Patients with respiratory failure increase ambulation after transfer to an intensive care unit where early activity is a priority. Crit Care Med 2008;36(4): 1119-1124.

67. Burtin C, Clerckx B, Robbeets C, Ferdinande P, Langer D, Troosters $\mathrm{T}$, et al. Early exercise in critically ill patients enhances short-term functional recovery. Crit Care Med 2009;37(9):2499-2505.

68. Schweickert WD, Pohlman MC, Pohlman AS, Nigos C, Pawlik AJ, Esbrook CL, et al. Early physical and occupational therapy in mechanically ventilated, critically ill patients: a randomised controlled trial. Lancet 2009;373(9678):1874-1882.

69. Brown SM, Rozenblum R, Aboumatar H, Fagan MB, Milic M, Lee BS, et al. Defining patient and family engagement in the intensive care unit. Am J Respir Crit Care Med 2015;191(3):358-360

70. Choi YJ, Baek JH, Ha EJ, Lim HK, Lee JH, Kim JK, et al. Differences in risk of malignancy and management recommendations in subcategories of thyroid nodules with atypia of undetermined significance or follicular lesion of undetermined significance: the role of ultrasound-guided core-needle biopsy. Thyroid 2014;24(3):494501.

71. Heyland DK, Rocker GM, Dodek PM, Kutsogiannis DJ, Konopad E, Cook DJ, et al. Family satisfaction with care in the intensive care unit: results of a multiple center study. Crit Care Med 2002;30(7): 1413-1418.

72. Wasser T, Pasquale MA, Matchett SC, Bryan Y, Pasquale M. Establishing reliability and validity of the critical care family satisfaction survey. Crit Care Med 2001;29(1):192-196.

73. Berger Z, Flickinger TE, Pfoh E, Martinez KA, Dy SM. Promoting engagement by patients and families to reduce adverse events in acute care settings: a systematic review. BMJ Qual Saf 2014;23(7): 548-555.

74. Azoulay E, Pochard F, Chevret S, Arich C, Brivet F, Brun F, et al.; French Famirea Group. Family participation in care to the critically ill: opinions of families and staff. Intensive Care Med 2003;29(9): 1498-1504.

75. Mitchell ML, Chaboyer W. Family Centred Care-A way to connect patients, families and nurses in critical care: A qualitative study using telephone interviews. Intensive Crit Care Nurs 2010;26(3): 154-160.

76. Mitchell M, Chaboyer W, Burmeister E, Foster M. Positive effects of a nursing intervention on family-centered care in adult critical care. Am J Crit Care 2009;18(6):543-552; quiz 553.

77. Garrouste-Orgeas M, Willems V, Timsit JF, Diaw F, Brochon S, Vesin A, et al. Opinions of families, staff, and patients about family participation in care in intensive care units. J Crit Care 2010;25(4): 634-640.

78. Davidson JE, Daly BJ, Agan D, Brady NR, Higgins PA. Facilitated sensemaking: a feasibility study for the provision of a family support program in the intensive care unit. Crit Care Nurs Q 2010;33(2): 177-189.

79. Marshall AP, Lemieux M, Dhaliwal R, Seyler H, MacEachern KN, Heyland DK. Novel, family-centered intervention to improve nutrition in patients recovering from critical illness: a feasibility study. Nutr Clin Pract 2017;32(3):392-399. 